\title{
Utility of uroflowmetry during the follow-up of children affected by balanitis xerotica obliterans (BXO)
}

\author{
Salvatore Arena, Tiziana Russo, Pietro Impellizzeri, Saveria Parisi, Patrizia Perrone, Carmelo Romeo \\ Department of Human Pathology in Adult and Developmental Age "Gaetano Barresi", Unit of Paediatric Surgery, \\ University of Messina, Italy.
}

\begin{abstract}
Summary Introduction: To evaluate the outcome of circumcised patients with balanitis xerotica

obliterans (BXO) using uroflowmetry (UF).

Methods: Between 2011 and 2013, 180 children underwent $a$ circumcision for phimosis. The foreskin was examined on microscopy. Patients with an histological diagnosis of $\mathrm{BXO}$ were included in the study. Patients with BXO underwent UF two weeks after surgery and treatment with clobetasol propionate ointment. Patients were re-evaluated at $6,12,18$ and 24 months postoperatively clinically and using UF.

Results: 75 of 180 circumcised patients (41.6\%) were included. At two weeks, Thirtytwo of 75 patients (42.7\%) displayed a pathological UF. At six months, 15 patients (20\%) had pathological UF and a new cycle of clobetasol was prescribed. At one year, 10 patients (13.3\%) displayed patholgocial UF and underwent progressive urethral dilatation or meatoplasty. At 18 months, 71 patients $(94.7 \%)$ displayed regular UF, 3 underwent a meatoplasty and one a staged urethroplasty for a severe urethral stenosis. At two years, UF was normal in 74 out of 75 (98.7\%).

Conclusions: We recommend to send for hystological examination all foreskins excised after circumcision. We believe that a clinical and uroflowmetric follow-up of pediatric patients with $\mathrm{BXO}$ is mandatory for a prompt identification of post-voiding dysfunction.
\end{abstract}

KEY WORDS: Phimosis; Balanitis xerotica obliterans; Uroflowmetry.

Submitted 3 April 2018; Accepted 29 April 2018

\section{INTRODUCTION}

Lichen sclerosus et atrophicus of the foreskin called also balanitis xerotica obliterans (BXO) is one of main causes of acquired phimosis $(1,2)$, firstly reported in pediatric age by Catterall in 1962 (2).

It is a chronic inflammatory disease of unclear etiology, which can affect the foreskin, frenulum, glans, meatus and urethra (1-3). It is believed that the real incidence of BXO is underestimated in the general population and $\mathrm{BXO}$ is considered uncommon in children (4). Significant obstructive complications secondary to phimosis complicated by BXO are described (5-7), among them urethral meatal stenosis is the most frequent one. As regards, recent studies report that 7-19\% of boys circumcised for BXO require a subsequent meatal procedure $(5,8-12)$ and a meatoplasty is required in up to $36 \%$ of cases (5). Rarely, BXO affects the urethra causing stenosis and, even if it is related to squamosus cell carcinoma in adulthood, no cases of malignant lesion are reported in pediatric age $(5,7,9)$.

Uroflowmetry (UF) has been traditionally used in the follow-up of patients with voiding dysfunction including children, because it is a simple, non invasive and unexpensive diagnostic tool $(13,14)$. Despite the welldescribed complications of BXO in term of obstructive uropathy, UF is not routinely used during post follow-up in patients undergoing circumcision with a histological diagnosis of BXO.

Aim of the study is to assess the short and long-term outcome of circumcised patients with BXO using UF, in order to identify early obstructive features related to this disease.

\section{Materials AND METHOdS}

Between January 2011 to December 2013, 180 children underwent a circumcision for clinical diagnosis of secondary phimosis at our Department. The foreskin was examined on light microscopy by a pathologist. Patients with an histological diagnosis of BXO were included in the study. BXO was defined as an epithelial-stromal lesion characterized by squamous atrophy or hyperplasia, band like infiltration, hyalinization of the papillary dermis, hyperkeratosis, pigment incontinence and/or dermal edema. We excluded from the study patients with pre-operative treatment with corticoid ointment or cream and without histologically proven BXO. A chart review was performed, collecting data relating to demographics, clinical presentation, histopathological findings, steroid therapy and follow-up.

Patients with BXO underwent UF two weeks after surgery and clobetasol propionate $0.05 \%$ ointment was applied once daily, at night, for 4 weeks, then on alternate nights for 4 weeks, and then twice weekly for a further 4 weeks, according to Pugliese JM et al. (15).

UF was carried out in a quiet and private room, with a comfortable environment to prevent any performance failure. An hour before the test, the children drank fluids for a total equal to the expected bladder capacity (age $\mathrm{x}$ $30 \mathrm{ml}+30 \mathrm{ml}$ ). The test was performed when the children felt the normal sensation of fullness in the bladder or in the presence of urinary urgency. Volume of $50 \mathrm{~mL}$ or more and between $50 \%$ and $100 \%$ if the expected 
bladder capacity were considered as relevant for interpretation. At least, two tests are usually done since high variability in UF tests could lead to a misleading diagnosis (16). Voided volume, $Q_{\max }$ (peak flow rate with a duration of at least two seconds) and uroflow curves were considered for interpretation of results.

Patients were re-evaluated at 6, 12, 18 and 24 months postoperatively clinically and using UF. The $\mathrm{Q}_{\max }$ was plotted on body surface related flow rate nomograms that correlate the voided volume of urine to the $\mathrm{Q}_{\max }$

The upper $95 \%$ tolerance limits for the $5^{\text {th }}, 10^{\text {th }}, 15^{\text {th }}, 20^{\text {th }}$ and $25^{\text {th }}$ percentiles of normal population were used for comparison. To interpret uroflow data we used flow rate nomograms proposed by Tonguri (17). The flow pattern was classified as bell ring, plateau or intermittent $(18,19)$.

\section{RESULTS}

75 out of 180 patients (41.6\%) with an histological diagnosis of BXO were included in the study. The mean age at diagnosis was $9.2 \pm 2.1$ years, ranging from 5 to 15 years. At two weeks, UF showed a mean $Q_{\max } 10.1 \pm 3.3 \mathrm{ml} / \mathrm{sec}$; 32 out of 75 patients ( $42.7 \%$ ) displayed a significant low $\mathrm{Q}_{\max }(6.7 \pm 1.4 \mathrm{ml} / \mathrm{sec})$ and a plateau flow pattern. At six months after surgery, all patients repeated UF, showing a mean $\mathrm{Q}_{\max } 11.9 \mathrm{ml} / \mathrm{sec} \pm 3.3 \mathrm{ml} / \mathrm{sec}$. Fifteen $(20 \%)$ of these patients had a significant low $\mathrm{Q}_{\max }$ and a plateau curve, with a mean $Q_{\max }$ of $5.9 \pm 0.7 \mathrm{ml} / \mathrm{sec}$, while 60 $(80 \%)$ patients had a normal $Q_{\max }$ of with a mean of 13.4 $\pm 1.5 \mathrm{ml} / \mathrm{sec}$ with bell ring flow pattern. We prescribed a new cycle of clobetasol topic treatment for 12 weeks in patients with obstructive pattern at UF.

At one year after surgery, overall mean $\mathrm{Q}_{\max }$ in $75 \mathrm{UF}$ was $13.0 \pm 2.5 \mathrm{ml} / \mathrm{sec}$ and 10 out of 75 patients (13.3\%) displayed a significant low $Q_{\max }$ and a pleateau flow pattern; 65 out of 75 patients showed normal $Q_{\max }(13.9 \pm$ $1.2 \mathrm{ml} / \mathrm{sec}$ ) with a bell ring UF pattern. The 10 patients with pathological UF $(7.3 \pm 0.6 \mathrm{ml} / \mathrm{sec})$ underwent progressive urethral dilatation (5 patients) and diagnostic cystoscopy (5 patients). In the latter, cistoscopy was negative for urethral pathology and a meatoplasty was performed. At 18 months, 71 out of 75 patients (94.7\%) displayed regular $\mathrm{Q}_{\max }$ according to age and bell ring flow pattern (mean $14.5 \pm 1.0 \mathrm{ml} / \mathrm{sec}$ ). Differently, 4 patients, that previously had undergone progressive urethral dilatation, showed low Qmax and a plateau flow pattern (mean $7.3 \pm 0.9 \mathrm{ml} / \mathrm{sec}$ ). A cistoscopy was then performed that was negative for urethral obstruction in 3 patients. The latter underwent a meatoplasty.

Differently, a severe urethral stenosis occurred in a patient

\section{Table 1.}

$Q_{\max }$ values in patients with histological BXO.

\begin{tabular}{|lccc|}
\hline & Normal UF & Patological UF & Overall \\
\hline 2 weeks & $12.6 \pm 1.6 \mathrm{ml} / \mathrm{sec}(43)$ & $6.7 \pm 1.4 \mathrm{ml} / \mathrm{sec}(32)$ & $10.1 \pm 3.3 \mathrm{ml} / \mathrm{sec}$ \\
\hline 6 months & $13.4 \pm 1.5 \mathrm{ml} / \mathrm{sec}(60)$ & $5.9 \pm 0.7 \mathrm{ml} / \mathrm{sec}(15)$ & $11.9 \pm 3.3 \mathrm{ml} / \mathrm{sec}$ \\
\hline 12 months & $13.9 \pm 1.2 \mathrm{ml} / \mathrm{sec}(65)$ & $7.3 \pm 0.6 \mathrm{ml} / \mathrm{sec}(10)$ & $13.0 \pm 2.5 \mathrm{ml} / \mathrm{sec}$ \\
\hline 18 months & $14.5 \pm 1.0 \mathrm{ml} / \mathrm{sec}(71)$ & $7.3 \pm 0.9 \mathrm{ml} / \mathrm{sec}(4)$ & $14,1 \pm 1.9 \mathrm{ml} / \mathrm{sec}$ \\
\hline 24 months & $14.8 \pm 2.2 \mathrm{ml} / \mathrm{sec}(74)$ & $\mathrm{N} / \mathrm{A}$ & $14.8 \pm 2.2 \mathrm{ml} / \mathrm{sec}$ \\
\hline
\end{tabular}

and a two stage buccal mucosal graft was started. At two years, $Q_{\max }$ was normal $(14.8 \pm 2.2 \mathrm{ml} / \mathrm{sec})$ with a bell ring UF pattern in 74 out of 75 (98.7\%) patients while it was not assessable in patient underwent first stage of buccal mucosal graft procedure.

Table 1 summarizes the results.

\section{Discussion}

Reviewing the literature, the incidence of $\mathrm{BXO}$ in patients with phimosis ranges from 5 to $50 \%$, with the peak of incidence at 7-8 years age (1).This difference in the studies could be due to various factors, including the different indications for circumcision and the assessment made by different specialists such as pediatricians, dermatologists, urologists and pediatrics surgeons (1-3). Usually, the diagnosis of BXO is initially clinical, displaying un-retractable foreskin, white xerotic appearance of glans and foreskin, dysuria and voiding disturbances. However, the final diagnosis needs to be confirmed by histological examination (20). Furthermore, clinical diagnosis seems to underestimate the real incidence of histological BXO. As regards, Bochove reported that the $50 \%$ of patients with BXO would not have been diagnosed if it was not carried out histological examination, and this data is also confirmed from studies in the adult population (10)

On a systematic histological study of foreskin of pediatric patients underwent a circumcision for phimosis, it has been documented that $45.1 \%$ of congenital phimosis and $62.3 \%$ of acquired phimosis had histological features of BXO (9). Kiss et al. (21) reported that $40 \%$ of children with phimosis treated by circumcision had a $\mathrm{BXO}$, with a higher incidence in patients aged between 9 and 11 years, and a secondary phimosis was found in $90-93 \%$ of the boys with BXO (21-22). Moreover, BXO was found in $52.6 \%$ of patients with phimosis under the age of five years (23). Recently, the incidence of the disease seems to be increased, with a peak between 9 and 11 years (5). It is unclear the reason of this increment, but an increased incidence could be linked to the fact that more foreskin samples have been sent for histopathological examination, due to surgeons awareness about this disease and the foreskin examination, that is performed with more suspicious (5). Furthermore, it has been reported an alarming increase of incidence of unrecognized diagnosis of BXO that is placed only when it is responsible of complications (4). We agree with some Authors' suggestion to performing routinely histological analysis of the foreskin after circumcision, to avoid potential complications related to BXO. In our experience, an histological diagnosis of BXO was done in $41.6 \%$ of children undergone circumcision for secondary phimosis, with an average age of 9.2 \pm 2.1 years. Data of our study confirmed those of literature.

Circumcision appears as the definitive treatment in $96 \%$ of cases in several studies ( 8 , 22-25) and the treatment with topical steroids following circumcision appears decisive for avoiding complications, the most common of which are stenosis of the 
meatus or urethra $(15,25,26,28)$. As regards, Kulkarni described 215 adult patients who underwent surgery for hystologically proven $\mathrm{BXO}$ involving the foreskin and the anterior urethra (20), Christman et al. described six cases of obstructive urinary complication secondary to BXO in children (7). Corbett et al. described meatus as abnormal o affected in 23\% patients with BXO at time of circumcision (29). In our experience, 8 patients underwent a successful meatoplasty (in 3 after failed cycles of progressive urethral dilatation), one patient healed after progressive urethral dilatation and another required a two stage urethral reconstruction for severe urethral stricture.

While rare, the morbidity that can result from progression of this disease can be significant, leading to obstructive disease with impaired bladder and renal function $(7,30)$.

The diagnosis of BXO can be straightforward with earlier diagnosis and we consider as mandatory the surveillance of patients with BXO following circumcision and to perform UF during follow-up for monitoring changes in urinary flow, evaluating response to topical therapy and deciding whether to switch to second-level exams and/or therapeutic management.

The UF test has gained wide acceptance, as the initial screening tool to evaluate voiding function in children because it is considered as a reliable test for the diagnosis and for the follow-up of post-voiding abnormality. As regards, it is traditionally used to evaluate the functional results following hypospadias repair to identify asymptomatic obstruction early, being considered the most accurate, physiologic and non invasive method of assessing bladder outflow obstruction (31).

In fact, it is well know that in the urethral strictures, $\mathrm{Q}_{\max }$ is diminished and the flow pattern loses is normal bell shape and becomes flattened (31). UF allowed us to identify 32 patients with voiding dysfunction out of 75 patients with a histological diagnosis of BXO (44\%) and to successfully and promptly treat them with medical or mini-invasive management in 31 cases (97\%), recording just one serious urethral lesion, requiring a major surgery.

\section{Conclusions}

We recommend that all foreskins excised after circumcision have to be sent for hystological examination for and earlier identification of BXO. We believe that a follow-up of pediatric patients with BXO is mandatory for a prompt identification of post-voiding dysfunction and that the non-invasive, well-accepted and reliable nature of the UF makes it a first tool for the diagnosis and evaluation of BXO related meatal and urethral complications.

\section{REFERENCES}

1. Jasaitiene D, Valiukeviciene S, Vaitkiene D, et al. Lichen sclerosus et atrophicus in pediatric and adult male patients with congenital and acquired phimosis. Medicina (Kaunas) 2008; 44:460-6.

2. Russo T, Currò M, Barbera A, et al. Expression of transglutami- nase in foreskin of children with balanitis xerotica obliterans. Int $J$ Mol Sci. 2016;17. pii: E1551.

3. Currò M, Russo T, Ferlazzo N, et al. Anti-inflammatory and tissue regenerative effects of topical treatment with ozonated olive oil/vitamin E acetate in balanitis xerotica obliterans. Molecules. 2018; 23. pii: E645.

4. Catterall RD, Oates JK. Treatment of balanitis xerotica obliterans with hydrocortisone injections. Br J Vener Dis. 1962; 38:75-7.

5. Celis S, Reed F, Murphy F, et al. Balanitis xerotica obliterans in children and adolescents: a literature review and clinical series. J Pediatr Urol. 2014; 10:34-9.

6. Gargollo PC, Kozakewich HP, Bauer SB, et al. Balanitis xerotica obliterans in boys. J Urol. 2005; 174:1409-12

7. Christman MS, Chen JT, Holmes NM. Obstructive complications of lichen sclerosus. J Pediatr Urol. 2009; 5:165-9.

8. Becker K. Lichen Sclerosus in boys. Dtsch Arztzebl Int. 2011; 108:53.

9. Clouston D, Hall A, Lawrentschuk N. Penile lichen sclerosus (balanitis xerotica obliterans). BJU Int. 2011; 108:14-9.

10. Bochove-Overgaauw DM, Gelders W, De Vylder AM. Routine biopsies in pediatric circumcision: (non) sense? J Pediatr Urol. 2009; 5:178-80

11. Holbrook C, Tsang T. Management of boys with abnormal appearance of meatus at circumcision for balanitis xerotica obliterans. Ann R Coll Surg Engl. 2011; 93:482-4.

12. Wilkinson DJ, Lansdale N, Everitt LH, et al. Foreskin preputioplasty and intralesional triamcinolone: a valid alternative to circumcision for balanitis xerotica obliterans. J Pediatr Surg. 2012; 47:756-9.

13. Alyami F, Farhat W, Figueroa VH, et al. Utility and cost-effectiveness of uroflowmetry in a busy pediatric urology practice. Can Urol Assoc J. 2014; 8:E615-8

14. Anwar A, Kurokawa Y, Takahashi M, et al. Functional evaluation of one-stage urethroplasty with parameatal foreskin flaps repair of hypospadias using uroflowmetry. Int J Urol. 2003; 10:297-301.

15. Pugliese JM, Morey AF, Peterson AC. Lichen sclerosus: review of the literature and current recommendations for management. J Urol. 2007; 178:2268-76.

16. Chang SJ, Yang SS. Variability, related factors and normal reference value of post-void residual urine in healthy kindergarteners. J Urol. 2009; 182:1933-8.

17. Toguri AG, Uchida T, Bee DE. Pediatric uroflow rate nomograms. J Urol. 1982; 127:727-31.

18. Siroky MB. Interpretation of urinary flow rates. Urol Clin North Am. 1990; 17:537-42

19. Austin PF, Bauer SB, Bower W, et al. The standardization of terminology of lower urinary tract function in children and adolescents Update report from the standardization committee of the International Children's Continence Society. Neurourol Urodyn. 2016; 35:471-81

20. Kulkarni S, Barbagli G, Kirpekar D, et al. Lichen sclerosus of the male genitalia and urethra: surgical options and results in a multicenter international experience with 215 patients. Eur Urol. 2009; 55:945-54

21. Edmonds EV, Hunt S, Hawkins D, et al. Clinical parameters in male genital lichen sclerosus: a case series of 329 patients. J Eur Acad Dermatol Venereol. 2012; 26:730-7. 
22. Kiss A, Király L, Kutasy B, et al. High incidence of balanitis xerotica obliterans in boys with phimosis: prospective 10-year study. Pediatr Dermatol. 2005; 22:305-8.

23. Meuli M, Briner J, Hanimann B, et al. Lichen sclerosus et atrophicus causing phimosis in boys: a prospective study with 5-year followup after complete circumcision. J Urol. 1994; 152:987-9.

24. Jayakumar S, Antao B, Bevington O, et al. Balanitis xerotica obliterans in children and its incidence under the age of 5 years. $J$ Pediatr Urol. 2012; 8:272-5.

25. Mattioli G, Repetto P, Carlini C, et al. Lichen sclerosus et atrophicus in children with phimosis and hypospadias. Pediatr Surg Int 2002; 18:273-5.

26. Depasquale I, Park AJ, Bracka A. The treatment of balanitis xerotica obliterans. BJU Int. 2000; 86:459-65.

27. Liatsikos EN, Perimenis P, Dandinis K, et al. Lichen sclerosus et atrophicus. Findings after complete circumcision. Scand J Urol Nephrol. 1997; 31:453-6.

28. Kizer WS, Prarie T, Morey AF. Balanitis xerotica obliterans: epidemiologic distribution in an equal access health care system. South Med J. 2003; 96:9-11.

29. Homer L, Buchanan KJ, Nasr B, et al. Meatal stenosis in boys following circumcision for lichen sclerosus (balanitis xerotica obliterans). J Urol. 2014; 192:1784-8

30. Sandler G, Patrick E, Cass D. Long standing balanitis xerotica obliterans resulting in renal impairment in a child. Pediatr Surg Int. 2008; 24:961-4.

31. González R, Ludwikowski BM. Importance of urinary flow studies after hypospadias repair: a systematic review. Int J Urol. 2011; 18:757-61.

\section{Correspondence}

Salvatore Arena, MD (Corresponding Author)

salarena@unime.it; tel +390902213014

Tiziana Russo, MD

Pietro Impellizzeri, MD

Saveria Parisi, MD

Patrizia Perrone, $M D$

Carmelo Romeo, MD

Department of human pathology in adult and developmental age "Gaetano Barresi", University of Messina, Unit of Paediatric Surgery AUO "Gaetano Martino", viale Gazzi, 98124 Messina, Italy 